\title{
Mental Predicate KNOW Subtypes KNOW and FEEL in Japanese: Natural Semantic Metalanguage
}

\author{
Luh Putu Ratnayanti Sukma \\ Pandan College, Denpasar, Bali, Indonesia \\ pratnays@gmail.com
}

\begin{abstract}
Goddard and Wierzbicka (2014) mentions the original meanings of mental predicate consisting of six types namely think, know, feel, see, hear, want and don't want. This finding was forwarded into Japanese by Asano Cavanagh (2015), and found 12 verbs of Japanese language that were matched with those found by Goddard and Wierzbicka (2014). Of the twelve mental predicates that were continued by Asano, the type KNOW is matched with the verb 知 る shiru in Japanese. KNOW 知る shiru has subtypes KNOW and SAY. Furthermore, the subtype has three sub-subtypes, namely KNOW and SAY SOME, KNOW and SAY ALL PARTS, and KNOW and SAY AT ALL (NO).
\end{abstract}

Keywords: mental predicate, know, type, subtype

\section{Pendahuluan}

Wierzbicka menyatakan bahwa untuk menentukan makna sebuah kata perlu diketahui struktur semantisnya. Wierzbicka (2014) menawarkan sebuah teori yang paling mendekati dalam menguraikan struktur semantis sebuah kata yaitu teori Metabahasa Semantik Alami (MSA) yang bekerja dengan menggunakan perangkat makna asali. Pada MSA untuk menggali makna verba keadaan diperlukan pembanding. Pembandingnya adalah komponen makna. Apabila properti semantis dari kata-kata tersebut berhasil diungkapkan dan dibandingkan satu sama lain, maka parafrasa makna lebih mudah dilakukan. Selanjutnya dari memparafrasakan makna inilah ditemukan struktur semantis dari sebuah verba keadaan sehingga adanya pemaknaan dari verba keadaan dan subtipe yang muncul dari verba keadaan tersebut. Wierzbicka menguraikan Metabahasa Semantik Alami memiliki 65 butir makna asali. Namun, ketika teori ini diteruskan ke dalam bahasa Jepang oleh 


\section{LUH PUTU RATNAYANTI SUKMA}

Asano-Cavanagh (2015) hanya ditemukan 63 butir. Sesuai dengan apa yang dipaparkan oleh Wierzbicka, dalam makna asali mental predicate ditemukan 6 subtipe verba, namun dalam padanannya yang dikemukakan oleh Asano dalam bahasa Jepang ditemukan 12 makna asali yang ada di dalam subtipe mental predicates.

Enam tipe dari verba keadaan yang dikemukakan oleh Goddard dan Wierzbicka (2014) kemudian diteruskan oleh Asano Cavanagh (2015) ke dalam bahasa Jepang. Dari hasil yang ditemukan, Asano menemukan 12 verba keadaan yang dipadankan dengan apa yang ditemukan oleh Goddard dan Wierzbicka (2014). Enam tipe yang ditemukan oleh Goddard dan Wierzbicka dan padanannya yang diteruskan oleh Asano (2015) adalah sebagai berikut:

$\begin{array}{ll}\text { Think } & \text { : 思う omou, 考える kangaeru } \\ \text { Know } & \text { : 知る shiru } \\ \text { Feel } & \text { : 感じる kanjiru } \\ \text { See } & \text { : 見る miru } \\ \text { Hear } & \text { : 聞く kiku } \\ \text { Want, don'twant } & :\{\text { :たいです-tai desu }\}, \text { ほしい hoshii, } \\ & \text { 望む nozomu } \\ & \{\text { 一たくないです-takunai desu }, \\ & \text { ほしくない hoshikunai, 望まない nozomanai }\end{array}$

Dari keenam tipe yang ditemukan, verba keadaan MENGETAHUI 知る shiru menghasilkan leksikon yang bervariasi dari subtipe yang ditemukan, dibandingkan dengan lima tipe lainnya. Verba keadaan tipe MENGETAHUI memiliki dua subtipe yaitu subtipe MENGETAHUI dan MENGATAKAN, MENGETAHUI dan MERASAKAN. Verba keadaan 知る shiru merupakan verba golongan I dalam bahasa Jepang. Verba dalam bahasa Jepang dibagi menjadi tiga golongan yaitu golongan I "godan doushi”, golongan II “ichidan doushi”, dan 
golongan III “henkaku doushi”. Subtipe verba keadaan 知る shiru, tersebar di dalam ketiga golongan verba yang ada dalam bahasa Jepang.

\section{Metode Penelitian}

Penelitian ini menggunakan metode penelitian kualitatif. Pendekatan kualitatif adalah suatu penelitian yang bertujuan memahami fenomena secara apa adanya (khususnya dari perspektif subjek) yang dideskripsikan dalam bentuk kata dan kalimat pada suatu konteks khusus yang alamiah (Moleong, 2004:11). Metode agih merupakan metode analisis menggunakan alat penentu yang merupakan bagian bahasa yang bersangkutan (Sudaryanto, 2015:18). Metode ini disertai dengan teknik ubah wujud parafrasal, yaitu mengubah wujud salah satu atau beberapa unsur satuan lingual yang bersangkutan (Sudaryanto, 2015:45).

\section{Teori}

Teori Metabahasa Semantik Alami (MSA) dalam penelitian ini berfungsi untuk menjelaskan makna asali dan struktur semantis dari VKBJ. Teori MSA dipelopori oleh Wierzbicka (1996). Teori ini dipilih berdasarkan bahwa MSA dapat mengekspresikan semua makna, naik makna leksikal, ilokusi, maupun makna leksikal yang dibingkai dalam sebuah metabahasa dan bersumber dari bahasa alamiah. Asumsi teori MSA berkaitan dengan prinsip semiotik yang menyatakan bahwa analisis makna menjadi tuntas. Makna kompleks dapat dijelaskan tanpa harus membingungkan dan tanpa residu dalam kombinasi makna diskret lainnya. Pengertian teoretis dari teori MSA dalam penelitian ini ada dua, yaitu makna asali dan polisemi takkomposisi. Makna asali merupakan seperangkat makna yang tidak dapat diubah karewa diwarisi oleh manusia sejak lahir (Goddard, 1996:2). Makna asali merupakan refleksi dari pikiran manusia yang mendasar, dapat dieksplikasikan dari bahasa alamiah yang merupakan satu-satunya cara dalam merepresentasikan makna (Wierzbicka, 1996:31). 


\section{Hasil dan Diskusi}

Tipe pengetahuan merupakan refleksi dari verba keadaan 知る shiru 'mengetahui'. Verba tipe pengetahuan memiliki dua subtipe yaitu MENGETAHUI dan MENGATAKAN, MENGETAHUI dan MERASAKAN. Subtipe ini dikandung oleh unsur-unsur yang melekat pada verba 知っています shitte imasu ‘mengetahui' dan ご存知です gozonji desu 'mengetahui’.
(4-1) この 花 を 知っていますか。見たことがありますか? kono hana wo shitte imasuka. Mita koto ga arimasuka ini bung AKU tahu BSTP lihat BPP

'Apakah anda tahu bunga ini ? apakah pernah melihatnya?'

(HT, 2017:3:5)

$\begin{array}{llllll}\text { (4-2) } & \text { 日本 } の & \text { 梅 } & \text { を } & \text { ご存知 } & \text { ですか } \\ \text { Nihon no } & \text { ume } & \text { wo } & \text { gozonji } & \text { desuka } \\ \text { Jepang GEN } & \text { ume } & \text { AKU } & \text { tahu-BSBP } & \text { KOPBB }\end{array}$

'Apakah anda tahu bunga Ume dari Jepang?'

(HT, 2017:3:18)

Kombinasi polisemi MENGETAHUI dan MENGATAKAN bisa dipilah lagi menjadi sub-subtipe MENGETAHUI dan MENGATAKAN SEBAGIAN dan SELURUH BAGIAN yang diketahui atau tidak bisa mengatakan SAMA SEKALI sesuatu atau seseorang yang sudah diketahui sebelumnya. Pengetahuan seseorang bisa diketahui dari apa yang dikatakan. Verba keadaan 覚える oboeru 'ingat' dalam bahasa Jepang mengandung kemampuan seseorang untuk mengatakan sebagian dari sesuatu atau seseorang. Berikut adalah pembahasannya:

Verba keadaan tipe MENGETAHUI dengan subtipe MENGETAHUI dan MENGATAKAN, menghasilkan 3 sub-subtipe yaitu MENGETAHUI dan MENGATAKAN SEBAGIAN, MENGETAHUI dan MENGATAKAN SELURUH BAGIAN, dan MENGETAHUI dan MENGATAKAN SAMA SEKALI (TIDAK). 
Mental Predicate KNOW Subtypes KNOW and FEEL in Japanese: ...

\begin{tabular}{|c|c|}
\hline $\begin{array}{c}\text { MENGETAHUI dan } \\
\text { MENGATAKAN }\end{array}$ & VERBA KEADAAN \\
\hline $\begin{array}{c}\text { MENGETAHUI dan } \\
\text { MENGATAKAN } \\
\text { SEBAGIAN }\end{array}$ & 覚える oboeru 'ingat' \\
\hline $\begin{array}{c}\text { MENGETAHUI dan } \\
\text { MENGATAKAN } \\
\text { SELURUH BAGIAN }\end{array}$ & 分かる wakaru 'paham' \\
\hline $\begin{array}{c}\text { MENGETAHUI dan } \\
\text { MENGATAKAN SAMA } \\
\text { SEKALI (TIDAK) }\end{array}$ & $\begin{array}{l}\text { 分かりません } \\
\text { wakarimasen } \\
\text { 'tidak paham' }\end{array}$ \\
\hline
\end{tabular}

Kombinasi polisemi takkomposisi MENGETAHUI dan MENGATAKAN bisa dipilah lagi menjadi sub-subtipe MENGETAHUI dan MENGATAKAN SEBAGIAN dan SELURUH BAGIAN yang diketahui atau tidak bisa mengatakan, SAMA SEKALI sesuatu atau seseorang yang sudah diketahui sebelumnya. Pengetahuan seseorang bisa diketahui dari apa yang dikatakan. Verba keadaan 覚 える oboeru 'ingat' dalam bahasa Jepang mengandung kemampuan seseorang untuk mengatakan sebagian dari sesuatu atau seseorang. Berikut adalah pembahasannya:

\subsection{Sub-subtipe MENGETAHUI dan MENGATAKAN SEBAGIAN}

Sub-subtipe MENGETAHUI dan MENGATAKAN SEBAGIAN diwujudkan dengan verba keadaan 覚える oboeru 'ingat'.

$\begin{array}{rllll}\text { (3.1-1) 電話 番号 } & \text { を } & \text { 覚える } & \text { ために } & \text { 自分で } \\ \text { denwa bangou } & \text { wo } & \text { oboeru } & \text { tameni } & \text { jibunde } \\ \text { nomor telepon } & \text { AKU } & \text { ingat BBP } & \text { untuk } & \text { sendiri }\end{array}$

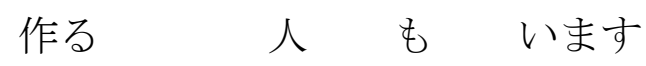




\section{LUH PUTU RATNAYANTI SUKMA}

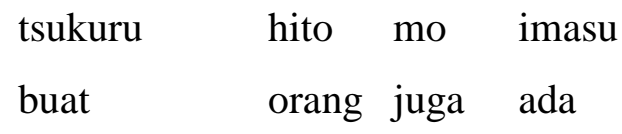

'Untuk memudahkan mengingat, ada juga orang yang sengaja membuat nomor teleponnya sendiri'

(HT, 2017:5:7)

Verba 覚える oboeru 'ingat' tidak harus ditafsirkan bahwa seseorang yang 覚える oboeru 'ingat' mampu mengatakan semua hal dari apa yang dia ingat “X tidak dapat mengatakan semua bagian dari Y'. Akan tetapi seseorang akan cenderung memiliki kemampuan untuk membangkitkan pengalaman yang pernah dialami di masa lalu dan mampu mengatakan sesuatu tentang bagian dari peristiwa yang dialami. Aktivitas mental berusaha memunculkan kembali sesuatu yang pernah dialami dan ternyata pada akhirnya tidak mampu mengatakan seluruh hal atau peristiwa yang dialami. Dalam struktur semantik, komponen yang dihasilkan adalah "X dapat mengatakan sesuatu tentang bagian dari $Y$ ".

Eksplikasi: 覚える oboeru 'ingat'

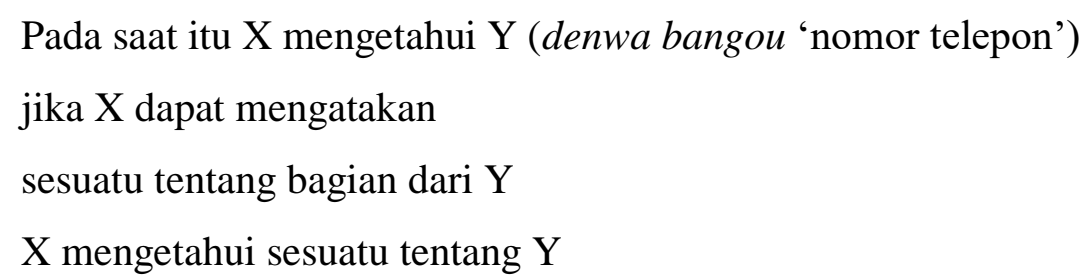

\subsection{Sub-subtipe MENGETAHUI dan MENGATAKAN SELURUH BAGIAN}

Sububtipe MENGETAHUI dan MENGATAKAN SELURUH SEBAGIAN diwujudkan dengan verba keadaan 分かる wakaru 'paham'.

$$
\begin{array}{rrlll}
\text { (3.2-1) 今 } & \text { まで } & \text { 数学 } & \text { が } & \text { 分かります } \\
\text { ima } & \text { made } & \text { suugaku } & \text { ga } & \text { wakarimasu } \\
\multicolumn{2}{r}{\text { sekarang sampai matematika }} & \text { PEM } & \text { paham BBP }
\end{array}
$$


'Sampai sekarang masih paham pelajaran Matematika.'

(HT, 2017:7:20)

Verba 分かる wakaru 'paham' mengindikasikan makna mengetahui dan bisa mengatakan tentang seluruh bagian dari sesuatu atau seseorang. Leksikon ini diwujudkan dengan polisemi MENGETAHUI dan MENGATAKAN yang memiliki kaidah sintaksis yaitu " $X$ mengetahui seluruh bagian dari sesuatu". Makna tersebut akan jelas tercermin dalam leksikon 分かる wakaru 'paham'.

Eksplikasi: 分かる wakaru 'paham'

Pada saat itu, X mengetahui tentang Y (suugaku 'matematika')

$\mathrm{X}$ berpikir seperti ini:

Jika X dapat mengatakan

semua bagian dari Y

$\mathrm{X}$ mengetahui sesuatu tentang $\mathrm{Y}$ seperti ini

4.3 Sub-subtipe MENGETAHUI dan MENGATAKAN SAMA SEKALI (TIDAK)

Sub-subtipe MENGETAHUI dan MENGATAKAN SAMA SEKALI (TIDAK) diwujudkan dengan verba keadaan 分かりません wakarimasen tidak paham'.

$\begin{array}{cllll}\text { (3.3-1) 去年 } & \text { 日本語 } & \text { が } & \text { ぜんぜん } & \text { 分かりませんでした } \\ \text { kyonen } & \text { nihongo } & \text { ga } & \text { zenzen } & \text { wakarimasen deshita } \\ \text { tahun lalu } & \text { bahasa Jepang PEM } & \text { sama sekali } & \text { tidak paham BLP }\end{array}$

'Tahun lalu, saya sama sekali tidak paham bahasa Jepang'

(HT, 2017:10:21)

Verba 分かりません wakarimasen ‘tidak paham’ mengindikasikan makna tidak mengetahui dan tidak bisa mengatakan tentang seluruh bagian dari sesuatu atau seseorang. Leksikon ini diwujudkan dengan polisemi MENGETAHUI dan 
MENGATAKAN yang memiliki kaidah sintaksis yaitu "X tidak mengetahui seluruh bagian dari sesuatu". Makna tersebut akan jelas tercermin dalam leksikon 分かりません wakarimasen 'tidak paham'.

Eksplikasi: 分かりません wakarimasen 'tidak paham’

Pada saat itu, X tidak mengetahui tentang Y (nihongo 'bahasa Jepang')

$\mathrm{X}$ berpikir seperti ini:

Jika $\mathrm{X}$ tidak dapat mengatakan

semua bagian dari Y

$\mathrm{X}$ tidak mengetahui sesuatu tentang Y seperti ini

\section{Simpulan}

Hasil dari penelitian ini menunjukkan verba keadaan MENGETAHUI memiliki 2 subtipe yaitu MENGETAHUI dan MENGATAKAN, MENGETAHUI dan MERASAKAN. Pada subtipe MENGETAHUI dan MENGATAKAN menghasilkan tiga sub-subtipe yaitu MENGETAHUI dan MENGATAKAN SEBAGIAN yang ditemukan pada verba keadaan 覚える oboeru 'ingat', MENGETAHUI dan MENGATAKAN SELURUH BAGIAN yang ditemukan pada verba keadaan 分かる wakaru 'paham', dan MENGETAHUI dan MENGATAKAN SAMA SEKALI (TIDAK) yang ditemukan pada verba keadaan 分かりません wakarimasen 'tidak paham'.

\section{Daftar Pustaka}

Asano-Cavanagh, Y. and G. M. Farese. 2015. “NSMセマンチクプライムのチャ 一ト”. Accessed 14 July, 2015. http://www.griffi th.edu.au/humanitieslanguages/school-languages-linguistics/research/natural-semanticmetalanguage homepage.

Chaer, Abdul. 2007. Linguistik Umum. Jakarta: Rineka Cipta.

Farese, Gian Marco. 2016. "The Cultural Semantics of Japanese Emotion Terms 'Haji' dan 'Hazukashii'”' (jurnal). Sidney: Australian National University.

Gande, Vinsensius. 2012. "Verba Memotong Dalam Bahasa Manggarai: Kajian Metabahasa Semantik Alami” (tesis). Denpasar: Universitas Udayana. 
Goddard, Cliff and Wierzbicka, Anna. 2014. Words and Meaning: Lexical Semantics accross Domains, Language, and Culture. United Kingdom: Oxford University Press.

Masreng, R. 2003. "Struktur dan Peran Semantis Verba dengan Makna 'Emosi' dalam Bahasa Kei” (tesis). Denpasar: Universitas Udayana.

Matsuura, Kenji. 2014. Kamus Jepang-Indonesia. Jakarta: PT. Gramedia Pustaka.

Mulyadi dan Siregar, Rumnasari K. 2006. “Aplikasi Teori Metabahasa Makna Alami dalam Kajian Makna” (jurnal). Sumatera Utara: Universitas Sumatera Utara.

Moloeng, Lexy J. 2004. Metodologi Penelitian Kualitatif. Bandung: Remaja Rosdakarya.

Neale, Miles. 2015. "A Comparison of English and Japanese Proverbs Using Natural Semantic Metalanguage". Sidney: The University of Queensland.

Purnawati, Ketut Widya. 2014. “Japanese Mental Predicate 'SEE' in Kanji 見る MIRU, 観る MIRU, 視る MIRU, 看る MIRU: A Natural Semantic Metalanguage Approach" (jurnal). Denpasar: Universitas Udayana.

84

Sudaryanto. 2015. Metode dan

Teknik Analisis Bahasa. Yogyakarta:

Sanatana Dharma University Press.

Sudipa, Henra Dwikarmawan Made. 2018. "Verba Majemuk Bahasa Jepang: Kajian Morfologi dan Metabahasa Semantik Alami”(tesis). Denpasar: Universitas Udayana.

Sudipa, I Nengah. 2004."Verba Bahasa Bali, sebuah Kajian Metabahasa Semantik Alami”. Denpasar: Universitas Udayana.

Sudipa, I Nengah. 2010. Struktur Semantik: Verba Keadaan Bahasa Bali. Denpasar: Udayana University Press.

Sudipa, I Nengah dan Jayantini. 2011. “ The English Mental Predicate 'KNOW' an NSM Approach”. Denpasar: Universitas Udayana.

Sudjianto, Dahidi. 2004. Pengantar Linguistik Bahasa Jepang. Jakarta: Kesaint Blanc.

Sutedi, Dedi. 2011. Dasar-dasar Linguistik Bahasa Jepang. Bandung: Humaniora Utama Press.

Wierzbicka, A. 1996. Semantics: Prime and Universal. Oxford: Oxford University. 